Revista Científica do Corpo de Bombeiros Militar de Pernambuco

XVIII Seminário Nacional de Bombeiros - Foz do Iguaçu PR

Vol.04 No11 - Edição Especial XVIII SENABOM - ISSN 2359-4829

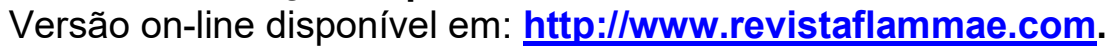

\title{
ESTUDO PROSPECTIVO DOS INCÊNDIOS E EXPLOSÕES EM UNIDADES INDUSTRIAIS DE BENEFICIAMENTO E ARMAZENAMENTO DE GRÃOS NO ESTADO DO PARANÁ
}

\section{PROSPECTIVE STUDY OF FIRES AND EXPLOSIONS IN INDUSTRIAL UNITS OF PROCESSING AND STORAGE OF GRAINS IN PARANA STATE}

\author{
Luis Eduardo Zarpellon ${ }^{l}$ \\ Camilo Freddy Mendoza Morejon ${ }^{2}$
}

\section{Resumo}

O estudo dos incêndios e explosões em Indústrias de Beneficiamento e Armazenamento de Grãos (IBAG's) é de fundamental importância para a tomada de decisões estratégicas antes, durante e depois das ocorrências. Assim, o objeto do trabalho foi explicitar o diagnóstico dos eventos, desta natureza, ocorridos no Estado do Paraná. A metodologia contemplou um estudo prospectivo, com base em pesquisa de campo e busca de informações no Sistema de Registro de Ocorrências e Estatísticas do Corpo de Bombeiros do Paraná (SYSBM), correspondente ao período entre 2005 e 2017. Os resultados apontam a existência de 2.819 unidades IBAG's, com registro de 495 ocorrências. A maior incidência ocorreu nas regiões norte, oeste e sudoeste paranaense. $\mathrm{O}$ tempo médio de atendimento foi de 5,5 horas e a principal fonte de risco foram os secadores de grãos $(77,24 \%)$.

Palavras-chave: Poeira. Explosão, Incêndio, Silos. Grãos.

\begin{abstract}
The study of fires and explosions in the Grain Processing and Storage Industries (IBAG's) is of fundamental importance for strategic decision making before, during and after occurrences. Thus, the purpose of the work was to explain the diagnosis of events, this nature, occurring in the Parana State. The methodology contemplated a prospective study, based on field research and information search in the System of Record of Occurrences and Statistics of Parana Fire Department (SYSBM), during the period between 2005 and 2017. The results indicate the existence of 2,819 IBAG's units, with a record of 495 occurrences. The highest incidence occurred in the northern, western and southwestern regions of Parana. The medium time of service was 5.5 hours and the main source of risk were grain dryers (77.24\%).
\end{abstract}

Key words: Dust. Explosion. Fire. Silos. Grains.

\footnotetext{
${ }^{1}$ Capitão do Corpo de Bombeiros da Polícia Militar do Paraná. Engenheiro Mecânico pela Universidade Tuiuti do Paraná. Mestrando em Engenharia Química pela Universidade Estadual do Oeste do Paraná. Email: zarpellon@pm.pr.gov.br

${ }^{2}$ Docente do Programa de Pós-Graduação em Engenharia Química da Universidade Estadual do Oeste do Paraná. E-mail: camilo_freddy@hotmail.com.
} 


\section{INTRODUÇÃO}

Segundo Florença (2014), nas atividades desenvolvidas com o processamento de grãos e seus derivados, existem potenciais de risco para todos os envolvidos na planta industrial (além dos riscos relacionados a segurança no trabalho), tais como incêndios e explosões nas instalações industriais, potencialmente provocados pelo pó em suspensão e em contato com uma fonte de ignição. Esses tipos de sinistros, são os que mais trazem danos ao patrimônio, bem como produzem perdas irreparáveis com relação à vidas e suas consequências psicológicas, dias parados em decorrência do acidente, perda no comércio e a competitividade no mercado, além do investimento necessário para a recuperação das perdas.

Segundo Sá (1998), as indústrias de processamento de produtos que em alguma de suas fases se apresentam na forma de pó são instalações de alto potencial de riscos quanto a incêndios e explosões. São indústrias de armazenagem, secagem e beneficiamento de produtos agrícolas, fabricantes de rações animais balanceadas, indústrias alimentícias (incluindo as fábricas de óleos vegetais), indústrias metalúrgicas, farmacêuticas, plásticas, de carvão e beneficiamento de madeira. Tais instalações devem, antes de sua implantação, efetuar uma análise acurada de seus riscos e tomar as precauções cabíveis, pois na fase de projeto as soluções são mais simples e econômicas. Porém as indústrias já implantadas, com o auxílio de um profissional competente, poderão equacionar razoavelmente bem os problemas, minorando os riscos inerentes.

No Brasil, a prevenção de incêndios nestas unidades ainda é incipiente quando comparada a países desenvolvidos como Alemanha e Suécia. Portanto, cabe aos Corpos de Bombeiros o entendimento da dinâmica dos incêndios e explosões nas plantas de grãos, haja vista as dificuldades encontradas em atendimentos desta natureza.

Segundo Persson (2013), o cenário mais difícil para o serviço do Corpo de Bombeiros é lidar com um incêndio profundo e latente, pois esses incêndios são extremamente difíceis de serem acessados. Como o fogo também é extremamente difícil de se detectar em fases iniciais há um risco de que já esteja difundido quando for 


\section{Revista FLAMMAE}

Revista Científica do Corpo de Bombeiros Militar de Pernambuco

XVIII Seminário Nacional de Bombeiros - Foz do Iguaçu PR

Vol.04 No11 - Edição Especial XVIII SENABOM - ISSN 2359-4829

Versão on-line disponível em: http://www.revistaflammae.com.

detectado. Se um incêndio profundo não é controlado, pode se desenvolver e possivelmente se alastrar no silo devido ao alto volume de gases que são gerados. Isso representa uma ameaça tanto para a estrutura do silo quanto para os sistemas de transporte adjacentes.

Diante deste contexto, este trabalho tem como propósito estudar os eventos de incêndios e explosões em Indústrias de Beneficiamento e Armazenamento de Grãos (IBAG's) no Estado do Paraná, no período de 2005 a 2017 para auxiliar nas ações de prevenção e combate a incêndios realizadas pelos Corpos de Bombeiros.

\section{DESENVOLVIMENTO}

A partir da metodologia prospectiva com pesquisa de campo, além da coleta de informações no Sistema de Registro de Ocorrências e Estatísticas do Corpo de Bombeiros do Paraná (SYSBM), correspondente ao período entre 2005 e 2017, foi possível explicitar: a) Diagnóstico das fontes de geração de risco de incêndios e explosões em IBAG`s; b) Diagnóstico das etapas do processo com potencial de risco de incêndio; c) Diagnóstico das etapas do processo com potencial de risco de explosões; d) Diagnóstico das ações de combate a incêndios.

\section{Diagnóstico das fontes de geração de risco de incêndios e explosões em IBAG`s}

Na Figura 1 se apresenta o detalhamento das Indústrias de Beneficiamento e Armazenamento de Grãos no Brasil. Conforme dados, no Brasil, até 2018 foram registrados 17.231 IBAG`s. O Estado de Sergipe apresenta o menor número de estabelecimentos de beneficiamento e armazenamento de grãos (3) e o Estado do Rio Grande do Sul é o que apresenta o maior número de IBAG`s (4.796). O estado do Paraná ocupa o segundo lugar com 2.819 IBAG`s, os quais se encontram concentrados na região Oeste paranaense.

Na Figura 2 se apresenta o número de ocorrências de incêndios e explosões registradas no Estado do Paraná entre os anos de 2005 e 2017. No total foram realizados 495 registros de incêndios, dos quais 11 foram precedidos de explosões. No ano de 2010 foram registrados 45 atendimentos, representando um aumento de $93,9 \%$ em 
Revista Científica do Corpo de Bombeiros Militar de Pernambuco

XVIII Seminário Nacional de Bombeiros - Foz do Iguaçu PR

Vol.04 No11 - Edição Especial XVIII SENABOM - ISSN 2359-4829

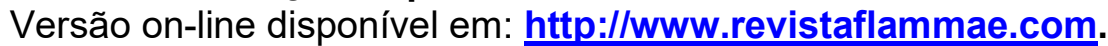

comparação a média dos anos anteriores, que era de 23,2 ocorrências ao ano. $\mathrm{O}$ ano de 2013 apresenta o maior índice de incêndios de todo período analisado. Com 64 registros, representa $12,9 \%$ de todas as ocorrências. No quadriênio pesquisado após 2013 se constata uma redução gradual no número registros.

Figura 1 - Indústrias de Beneficiamento e Armazenamento de Grãos no Brasil

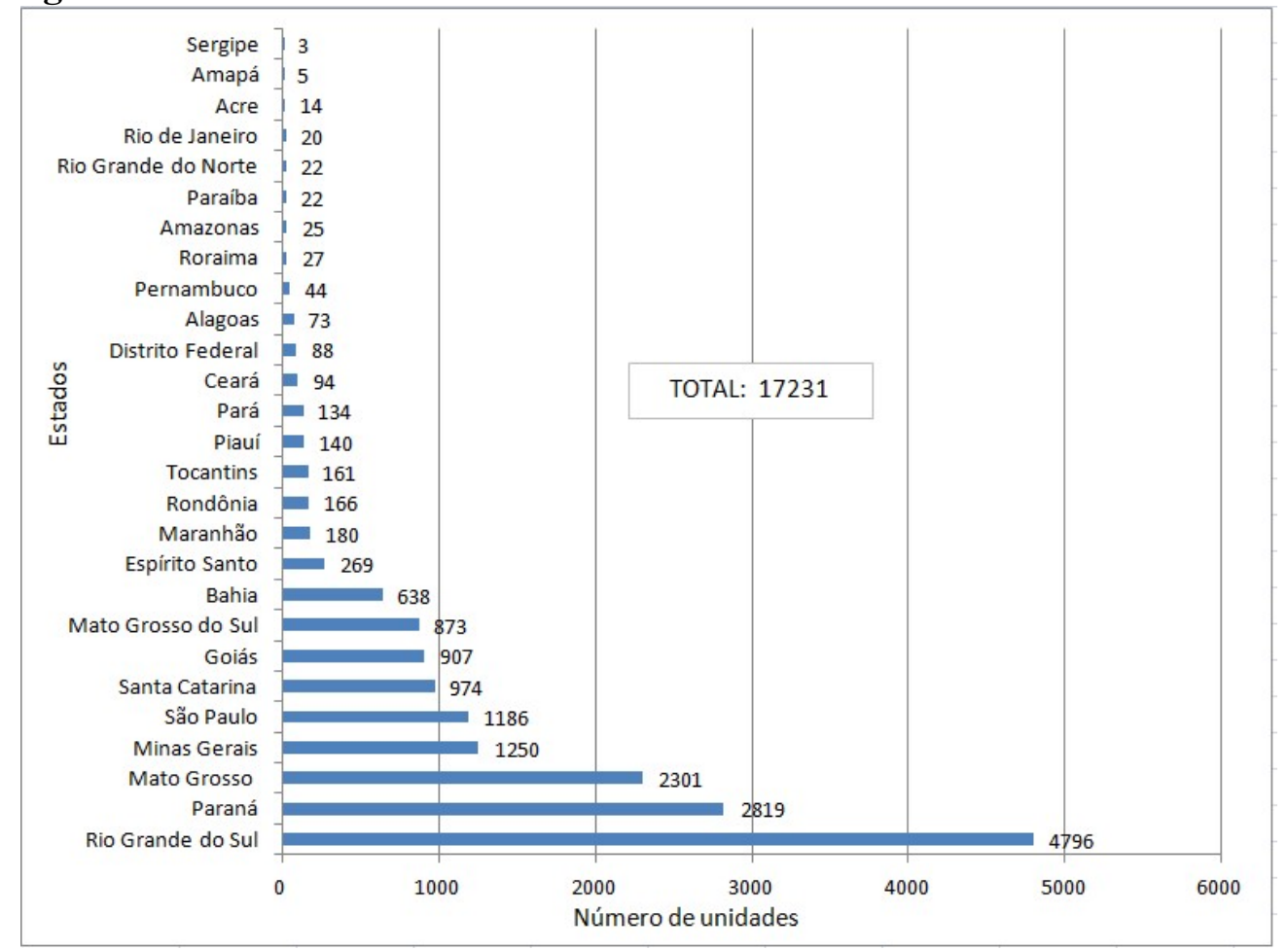

Fonte: SICARM - Sistema de Cadastro Nacional de Unidades Armazenadoras (CONAB Companhia Nacional de Abastecimento) (2018) 
Revista Científica do Corpo de Bombeiros Militar de Pernambuco

XVIII Seminário Nacional de Bombeiros - Foz do Iguaçu PR

Vol.04 N011 - Edição Especial XVIII SENABOM - ISSN 2359-4829

Versão on-line disponível em: http://www.revistaflammae.com.

Figura 2 - Incêndios em indústrias de beneficiamento e armazenamento de grãos no Estado do Paraná de 2005 a 2017

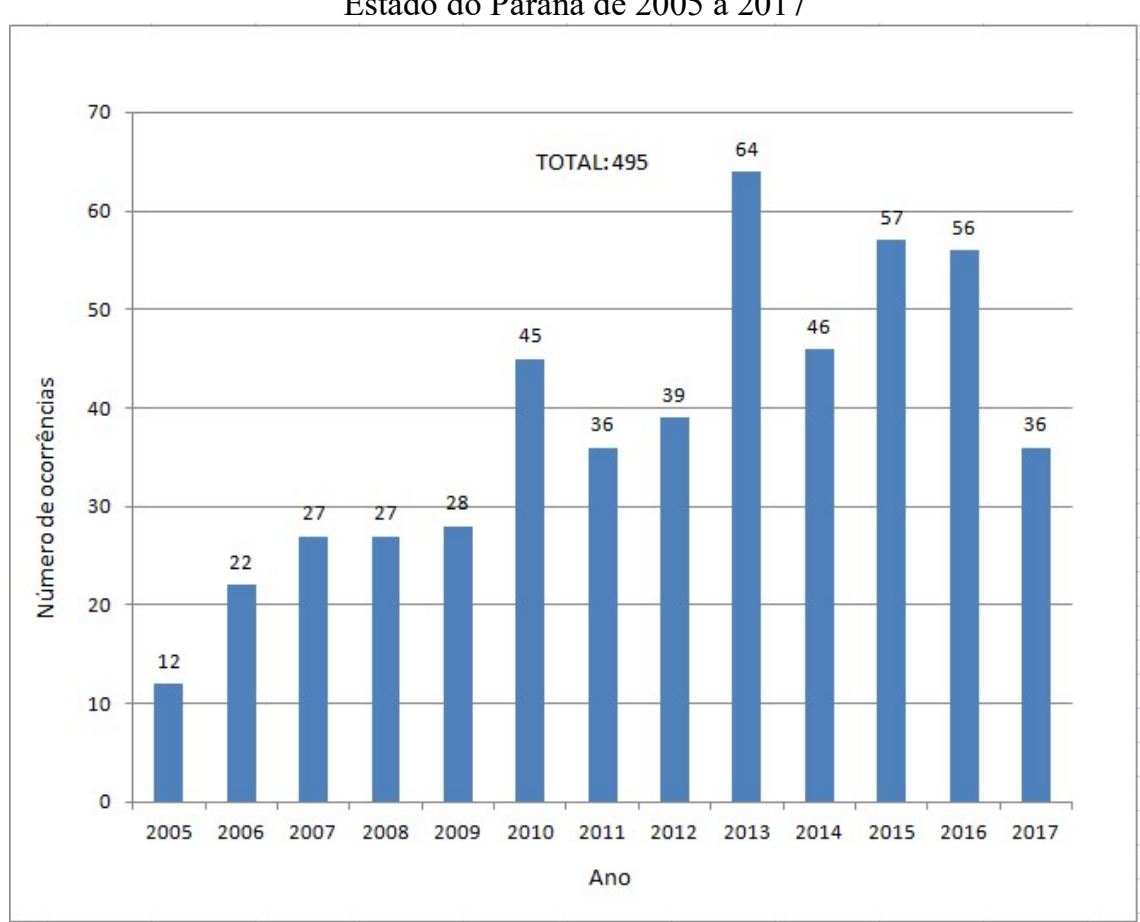

Fonte: SYSBM - Sistema de Registro de Ocorrências e Estatísticas do Corpo de Bombeiros do Paraná (2018)

A Figura 3 apresenta as regiões do Estado do Paraná onde foram registradas as maiores incidências dos incêndios em IBAG's. As maiores concentrações estão nas regiões norte, oeste e sudoeste paranaense. Dentro destas áreas, se destacam as microrregiões dos municípios de Cascavel e Londrina. 
Revista Científica do Corpo de Bombeiros Militar de Pernambuco

XVIII Seminário Nacional de Bombeiros - Foz do Iguaçu PR

Vol.04 No11 - Edição Especial XVIII SENABOM - ISSN 2359-4829

Versão on-line disponível em: http://www.revistaflammae.com.

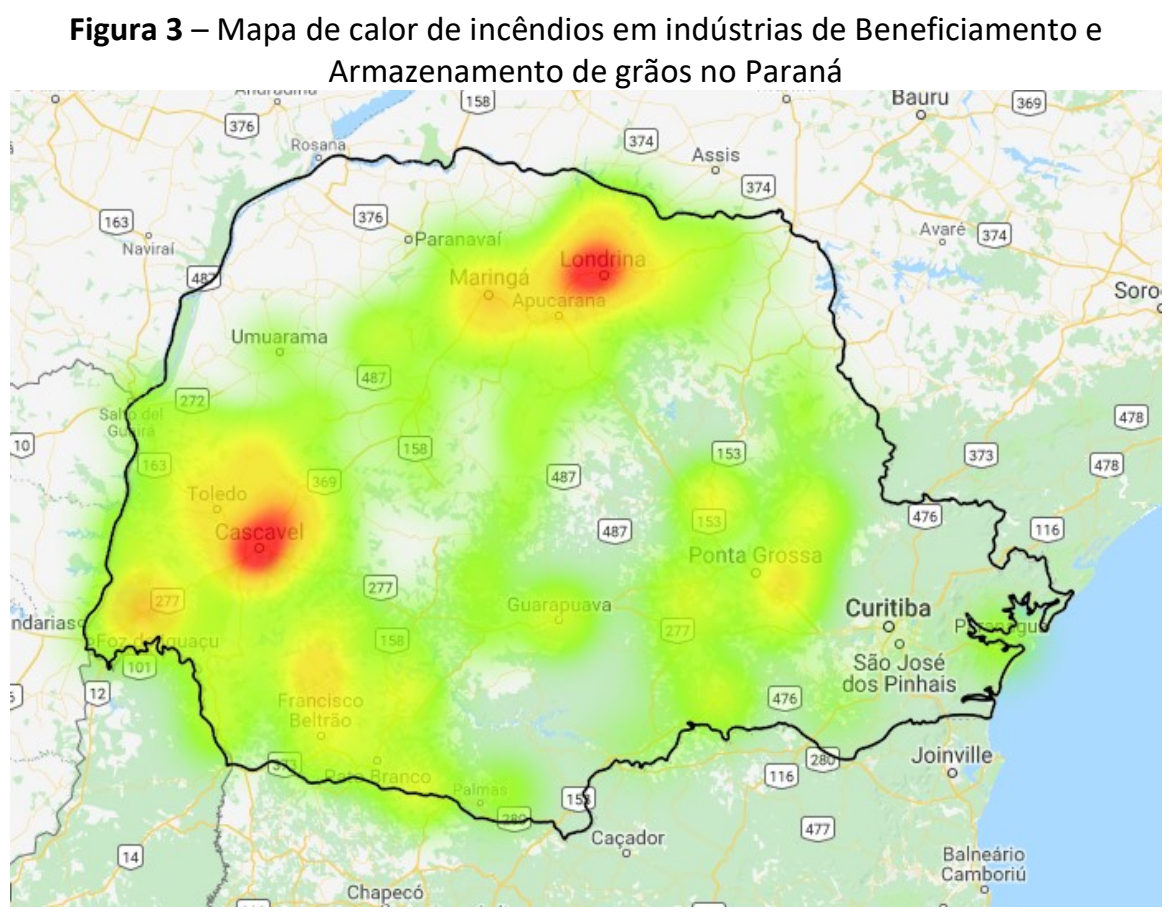

Fonte: SYSBM - Sistema de Registro de Ocorrências e Estatísticas do Corpo de Bombeiros do Paraná (2018)

\section{Diagnóstico das etapas do processo com potencial de risco de incêndio}

$\mathrm{Na}$ Tabela 1 se apresenta os locais com maior potencial de incêndios. Foi constatado que os incêndios estão restritos a oito locais: depósito de lenha, depósito de resíduos, elevador de grãos, esteira transportadora, filtro de manga, fornalha, secador de grãos e silo. Dos 495 registros, apenas 16 não indicam o local dentro da planta onde se sucedeu a ocorrência. Os incêndios registrados em fornalhas dizem respeito a materiais localizados nas adjacências do equipamento, os quais foram atingidos por fonte de calor oriunda da própria fornalha. 
Revista Científica do Corpo de Bombeiros Militar de Pernambuco

XVIII Seminário Nacional de Bombeiros - Foz do Iguaçu PR

Vol.04 No11 - Edição Especial XVIII SENABOM - ISSN 2359-4829

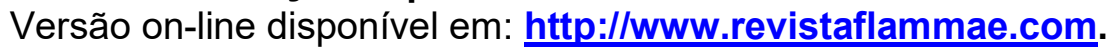

Tabela 1 - Locais dos incêndios

\begin{tabular}{|l|c|}
\hline Local do Incêndio & TOTAL \\
\hline Depósito de lenha & 5 \\
\hline Depósito de resíduos & 8 \\
\hline Elevador de grãos & 24 \\
\hline Esteira transportadora & 17 \\
\hline Filtro de manga & 4 \\
\hline Fornalha & 6 \\
\hline Secador de grãos & 370 \\
\hline Silo & 45 \\
\hline SUBTOTAL & $\mathbf{4 7 9}$ \\
\hline Não apurado & 16 \\
\hline TOTAL & $\mathbf{4 9 5}$ \\
\hline
\end{tabular}

Fonte: SYSBM - Sistema de Registro de Ocorrências e Estatísticas do Corpo de Bombeiros do Paraná (2018)

A Figura 4 demonstra o percentual dos locais de incêndios registrados dentro das IBAG's. Somente os secadores de grãos, respondem por 77,24\% dos atendimentos. Este tipo de incêndio, além de ser o mais frequente, é o que despende maior trabalho para ser extinto devido a suas peculiaridades.

Figura 4 - Percentual dos locais de incêndios em IBAG's

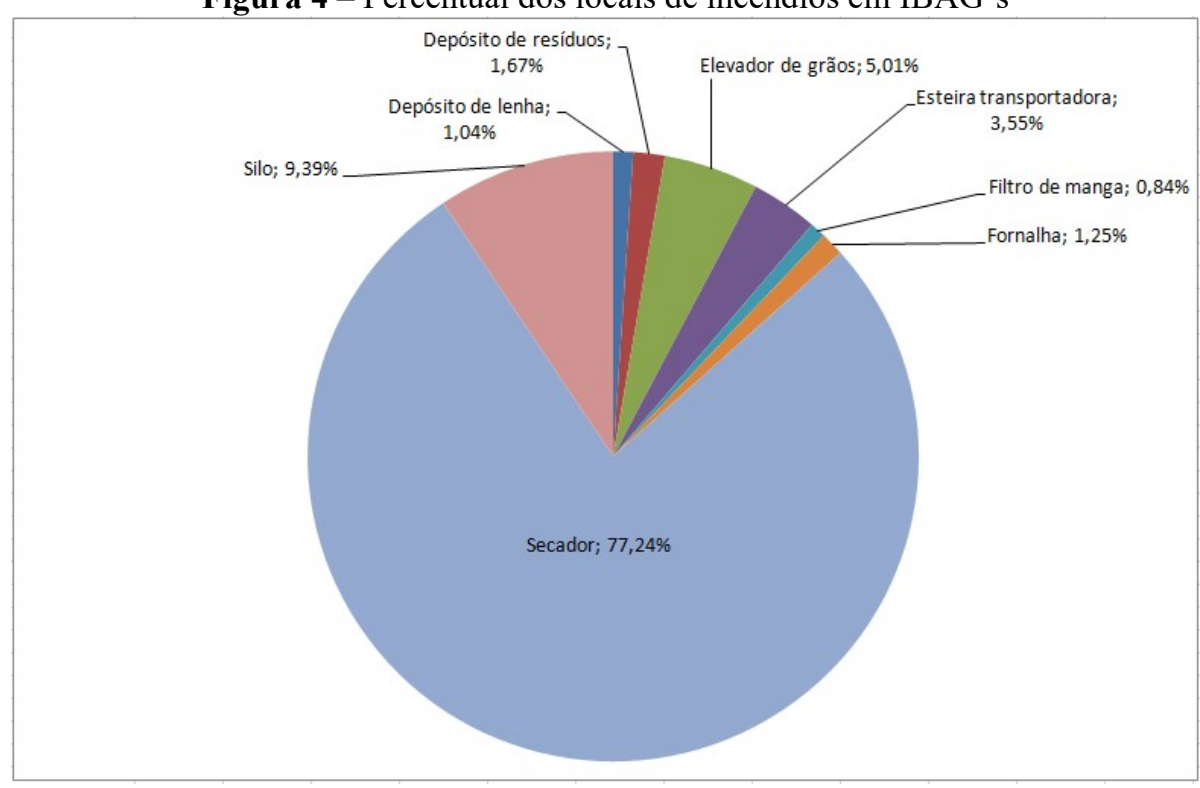

Fonte: SYSBM - Sistema de Registro de Ocorrências e Estatísticas do Corpo de Bombeiros do Paraná (2018) 
Segundo Sá (1998), os secadores normalmente possuem sua matriz de aquecimento a fogo vivo, a lenha, sendo o risco uma constante neste setor, neles é que geralmente se iniciam os incêndios e explosões, e em face da elevada quantidade de material em seu interior, a extinção é muito difícil.

Conforme Manual de Operação e Manutenção: Secadores de Coluna COMIL (2011), quando detectado ainda em sua fase inicial, os incêndios em secadores podem ser controlados pelo método de abafamento. Em caso de incêndios, o operador deve fechar todas as entradas de ar do secador, eliminando a entrada de oxigênio para o interior do equipamento, pois sem oxigênio não há combustão. Além disso, deve-se imediatamente desligar os ventiladores e acionar as tampas abafadoras instaladas sob os mesmos, parar de alimentar a fornalha com lenha e fechar todos os registros de ar do secador e da fornalha. Quando o fogo parar, descarregar o produto e limpar rigorosamente o secador. Caso o foco de incêndio já esteja em proporções maiores, recomenda-se além de abafar o secador, conforme mencionado, fazer simultaneamente a descarga e carga do produto, retirando da torre o produto sobre aquecido causador da propagação do incêndio e colocando produto úmido para completar a torre.

Entretanto, em alguns casos, os processos acima descritos se tornam impraticáveis por dois motivos. Por serem antigos, alguns equipamentos não possuem sistemas de abafamento, impossibilitando, portanto, manobras de extinção das chamas. Outro fator é o acionamento tardio do Corpo de Bombeiros. Desta forma, para os casos de incêndios em secadores já na fase totalmente desenvolvida, não é possível fazer a descarga do produto, haja vista a formação de blocos fundidos de grãos que impedem o fluxo de descarregamento.

Esse fato pode ser ilustrado na Figura 5, no qual se observa grãos de soja fundidos e a obstrução da descarga do secador, ambos os casos correspondentes a um incêndio ocorrido em 2017 no município de Tupãssi-PR.

Figura 5 - a) Grãos de soja fundidos, e b) Obstrução da descarga do secador por grãos de soja fundidos

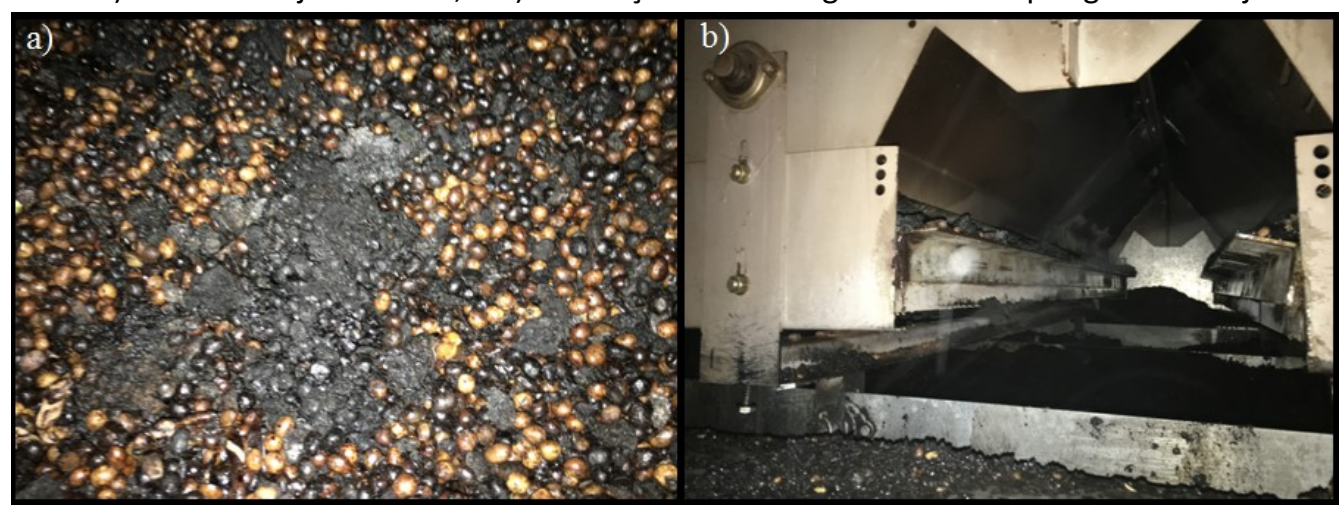

Fonte: Acervo do autor (2017) 
O comportamento estrutural do equipamento frente a caloria do incêndio é outro fator a ser levado em conta durante atendimento.

Na Figura 6 se apresenta deformação por fluência em função do tempo. Nessa propriedade prevalece a influência da temperatura $(T)$ e da tensão $(\sigma)$.

Segundo Callister (2008), tensões térmicas, que são introduzidas em um corpo como consequência de variações na temperatura, podem levar à fratura ou a uma deformação plástica indesejável. As duas principais fontes de tensões térmicas são a restrição à expansão (ou a contração) térmica e aos gradientes de temperatura que são estabelecidos durante o aquecimento ou o resfriamento.

Portanto, quanto maior a temperatura, maior será a deformação causada pela fluência. Logo, a possibilidade de colapso estrutural de um secador de grãos deve ser levada em conta durante o combate ao incêndio.

Figura 6 - Influência da tensão $\sigma$ e da temperatura $T$ sobre o comportamento da fluência

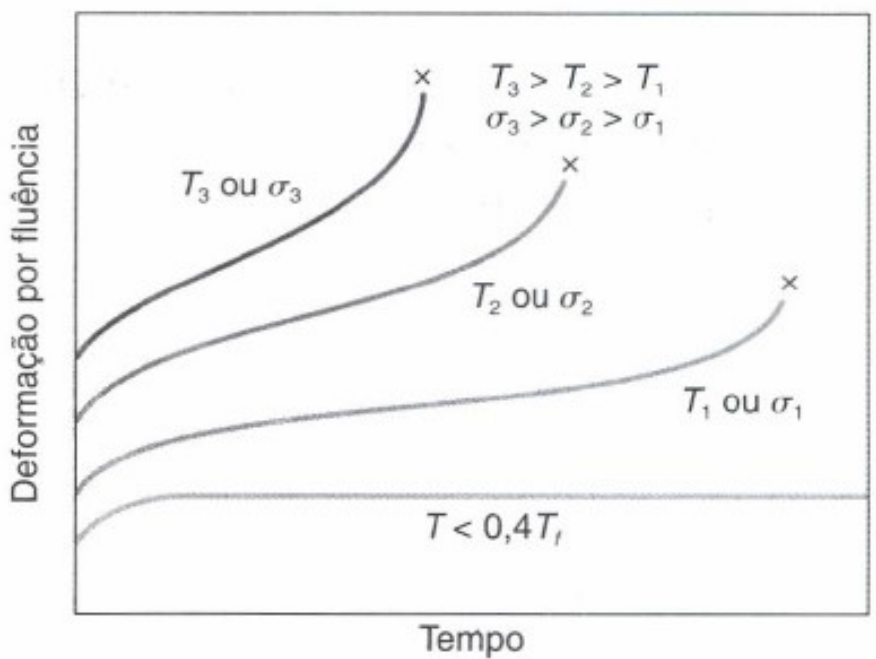

Fonte: Callister (2008)

Na Figura 7 podem ser observados indicativos de anormalidades, como superaquecimento e deformações plásticas, causadas por um incêndio ocorrido em 2017 no município de Tupãssi-PR. Nos casos mais extremos, estes fenômenos podem ser facilmente identificados sem auxílio de equipamentos. 
Revista Científica do Corpo de Bombeiros Militar de Pernambuco XVIII Seminário Nacional de Bombeiros - Foz do Iguaçu PR

Vol.04 No11 - Edição Especial XVIII SENABOM - ISSN 2359-4829

Versão on-line disponível em: http://www.revistaflammae.com.

Figura 7 - Anormalidades causadas por um incêndio: a) Detalhe de estrutura metálica de secador de grãos superaquecida, e b) Deformação plástica de secador de grãos

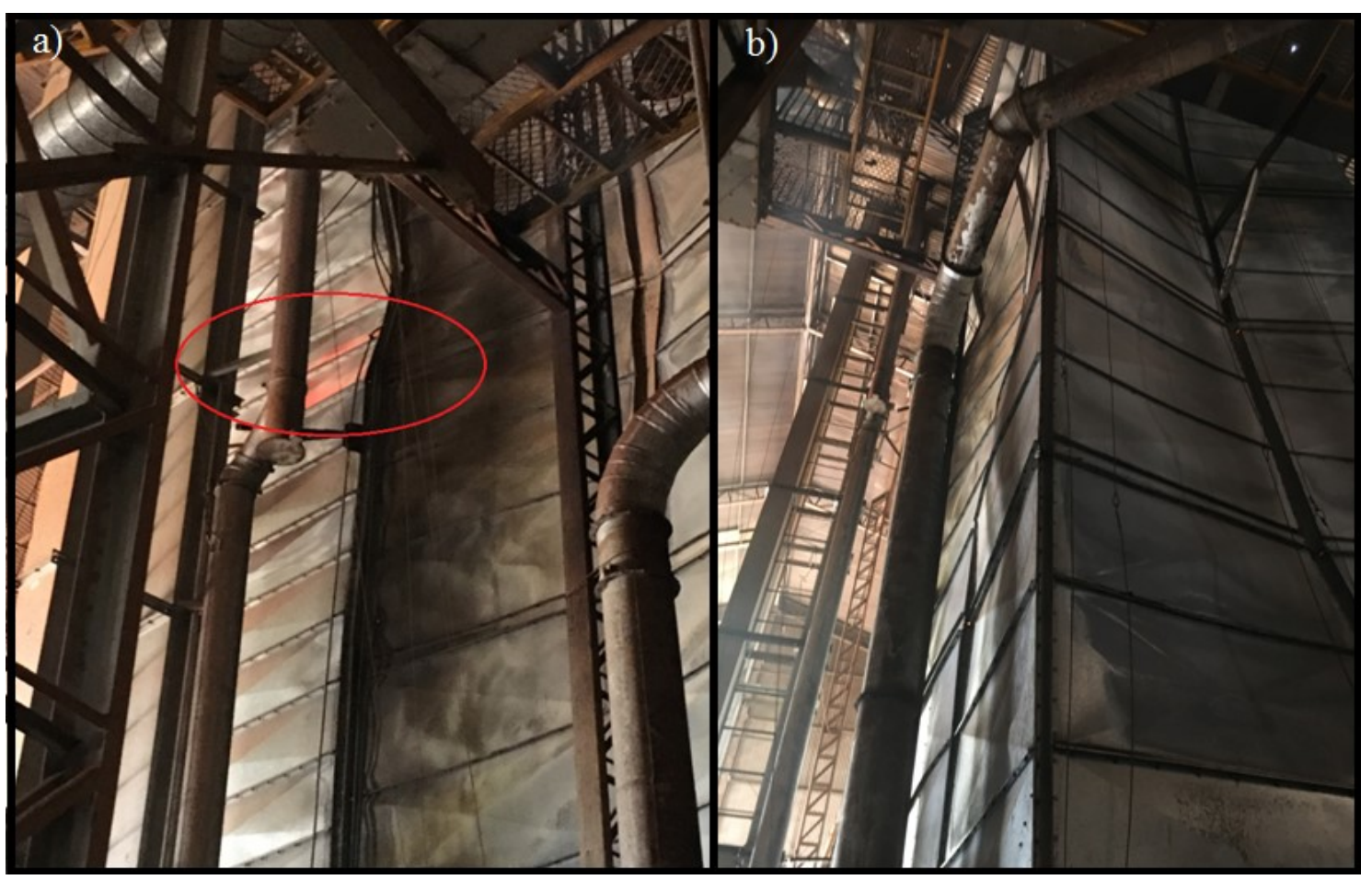

Fonte: Acervo do autor (2017)

\section{Diagnóstico das etapas do processo com potencial de risco de explosões}

Na Tabela 2 se apresenta o histórico de ocorrências de explosões em IBAG's no Estado do Paraná. Excluem-se desta lista explosões registradas em outros tipos de indústrias, como fecularias, fábricas de fertilizantes, usinas de açúcar e madeireiras.

Segundo Silva (1999), as explosões em unidades armazenadoras geralmente possuem por material explosivo a mistura das substâncias: ar atmosférico e partículas sólidas em suspensão, as quais neste caso são denominadas como os agentes comburentes e combustível, respectivamente. As partículas originam-se das impurezas que acompanham a massa de grãos ou do esfacelamento dos grãos.

Embora com número de registros em menor quantidade, a explosão de poeira é uma modalidade de ocorrência que desperta grande preocupação devido ao elevado potencial de destruição das plantas e mortes de trabalhadores.

Conforme ilustrado na Figura 8, as explosões causam grandes danos econômicos com desdobramento diretos e indiretos na sociedade. 
Revista FLAMMAE

Revista Científica do Corpo de Bombeiros Militar de Pernambuco

XVIII Seminário Nacional de Bombeiros - Foz do Iguaçu PR

Vol.04 No11 - Edição Especial XVIII SENABOM - ISSN 2359-4829

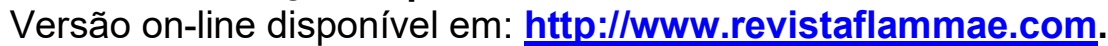

Tabela 2 - Explosões de poeira em unidades de beneficiamento e armazenamento de grãos no Paraná

\begin{tabular}{|c|l|c|l|}
\hline Ano & \multicolumn{1}{|c|}{ Cidade } & Data & \multicolumn{1}{c|}{ Local da Explosão } \\
\hline 2005 & Maringá & $04 / 02 / 2005$ & Esteira transportadora de túnel \\
\hline 2006 & Guarapuava & $12 / 02 / 2006$ & Silo \\
\hline 2008 & Londrina & $05 / 05 / 2008$ & Silo \\
\hline 2010 & Cascavel & $09 / 11 / 2010$ & Silo \\
\hline 2012 & Toledo & $22 / 03 / 2012$ & Silo \\
\hline 2013 & Londrina & $18 / 11 / 2013$ & Elevador de grãos \\
\hline 2013 & Cascavel & $26 / 09 / 2013$ & Elevador de grãos \\
\hline 2015 & Brasilândia do Sul & $01 / 02 / 2015$ & Silo \\
\hline 2016 & Cambé & $30 / 06 / 2016$ & Elevador de grãos \\
\hline 2016 & $\begin{array}{l}\text { Marechal Cândido } \\
\text { Rondon }\end{array}$ & $03 / 05 / 2016$ & Elevador de grãos \\
\hline & $\begin{array}{l}\text { Marechal Cândido } \\
2016\end{array}$ & $26 / 07 / 2016$ & Secador \\
\hline
\end{tabular}

Fonte: SYSBM - Sistema de Registro de Ocorrências e Estatísticas do Corpo de Bombeiros do Paraná (2018)

Segundo Persson (2013), o manuseio normal de materiais em plantas de silos gera sempre mais ou menos formação de poeira, que eventualmente cobre todas as superfícies horizontais e componentes de construção. Se alguma dessa poeira estiver dispersa em uma nuvem e houver uma fonte de ignição presente, pode ocorrer uma explosão. Este tipo de explosão é denominada de primária, a qual muitas vezes levanta poeira acumulada causando a explosão secundária, podendo ser significativamente mais poderosa que a explosão primária.

Figura 8 - Danos causados por explosão de poeira em estrutura de silos verticais em Brasilândia do Sul-PR

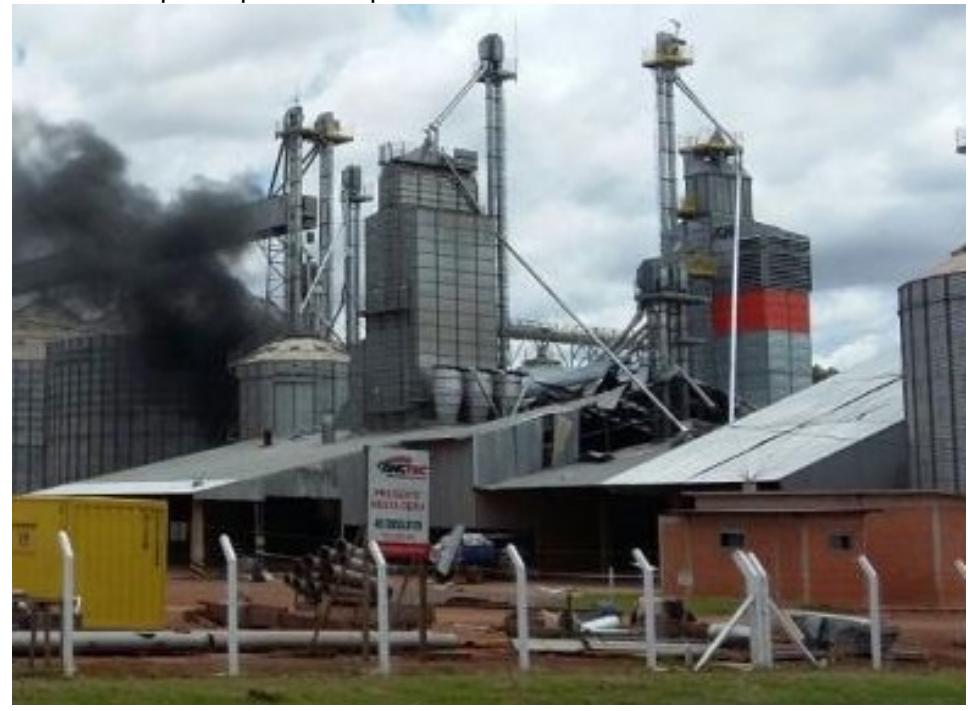

Fonte: Arquivo pessoal / Carlos Fernandes dos Anjos (2015) 
Revista Científica do Corpo de Bombeiros Militar de Pernambuco

XVIII Seminário Nacional de Bombeiros - Foz do Iguaçu PR

Vol.04 No11 - Edição Especial XVIII SENABOM - ISSN 2359-4829

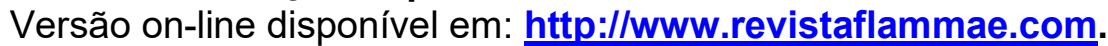

A Figura 9 corresponde a uma explosão secundária ocorrida em 2016, em uma cooperativa de grãos na cidade de Marechal Cândido Rondon-PR, que teve como causa a realização de solda em um dos elevadores de grãos.

Figura 9 - Danos causados por explosão secundária de poeira: a) Danos em túnel de silo graneleiro, e b) Danos em cobertura e sistema de ventilação de silo graneleiro

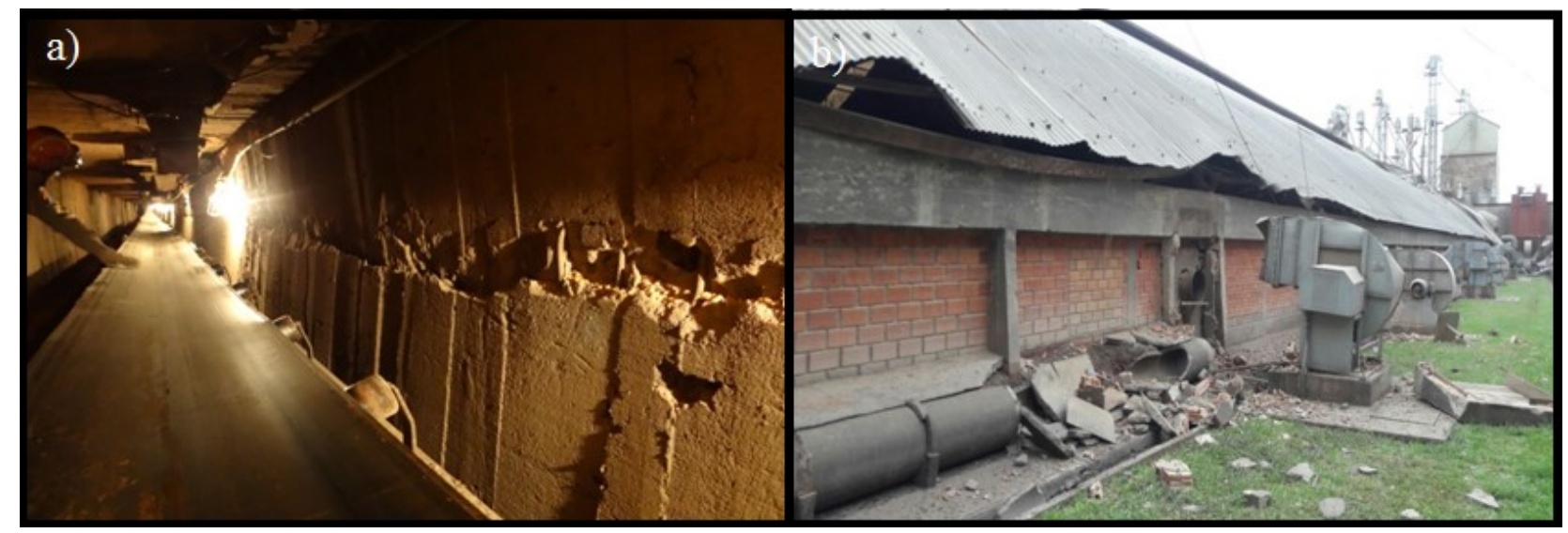

Fonte: Acervo do autor (2016)

\section{Diagnóstico das ações de combate aos incêndios}

Conforme Figura 10, se verifica que os incêndios são divididos em quatro fases, sendo elas: fase inicial, fase crescente, fase totalmente desenvolvida e fase final.

Geralmente, no momento da chegada das viaturas de combate a incêndios, as equipes de bombeiros já encontram o incêndio na fase totalmente desenvolvida. Não há, portanto, eficácia na salvaguarda do patrimônio em razão do alastramento do fogo.

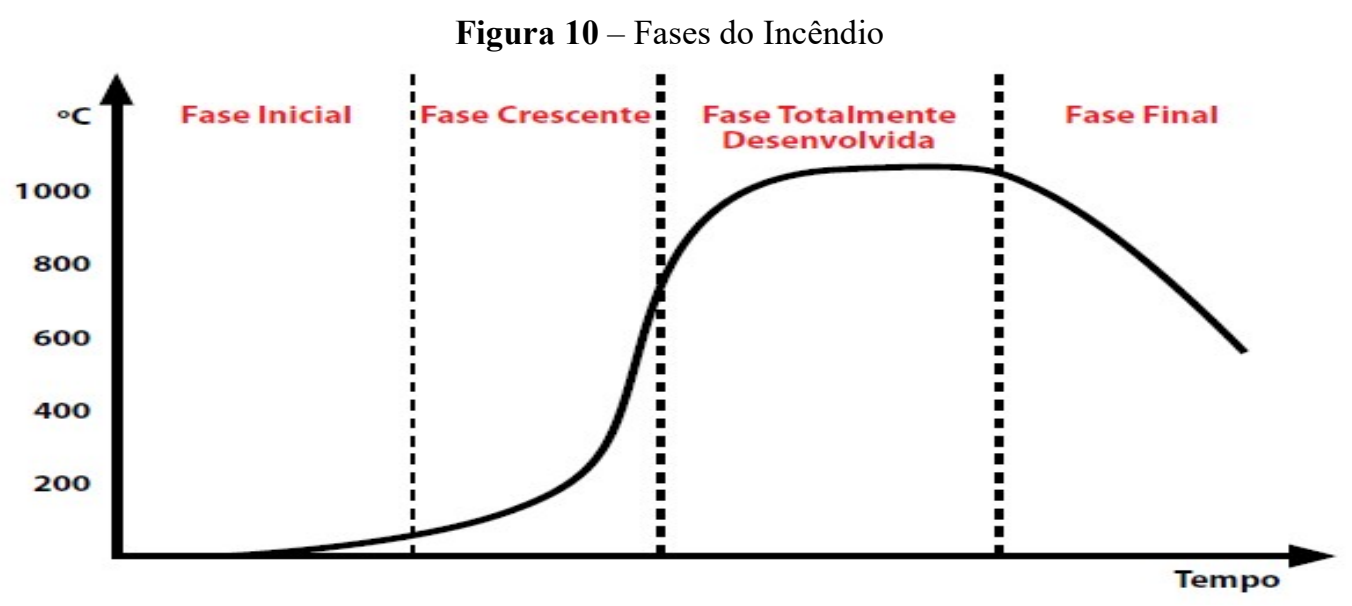

Fonte: Tactical Firefighting, Paul Grimwood (2003) 
Revista Científica do Corpo de Bombeiros Militar de Pernambuco XVIII Seminário Nacional de Bombeiros - Foz do Iguaçu PR Vol.04 N011 - Edição Especial XVIII SENABOM - ISSN 2359-4829

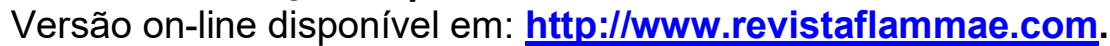

Conforme Figura 11, as IBAG's são compostas por conjunto de equipamentos em série como, esteiras transportadoras, elevadores de grãos, máquinas de pré-limpeza, filtros de manga, secadores de grãos e silos. Alguns destes equipamentos estão localizados em túneis subterrâneos, passarelas elevadas e fossos, ou necessitam ser acessados por escadas. Na maioria dos casos, o acesso aos locais das chamas é dificultoso. A realização do combate aos incêndios requer, portanto, a utilização de sistemas verticais de segurança individual, e em alguns casos sistemas verticais para facilitar o uso das mangueiras.

Figura 11 - Dificuldade de acesso aos focos de incêndios em IBAG's

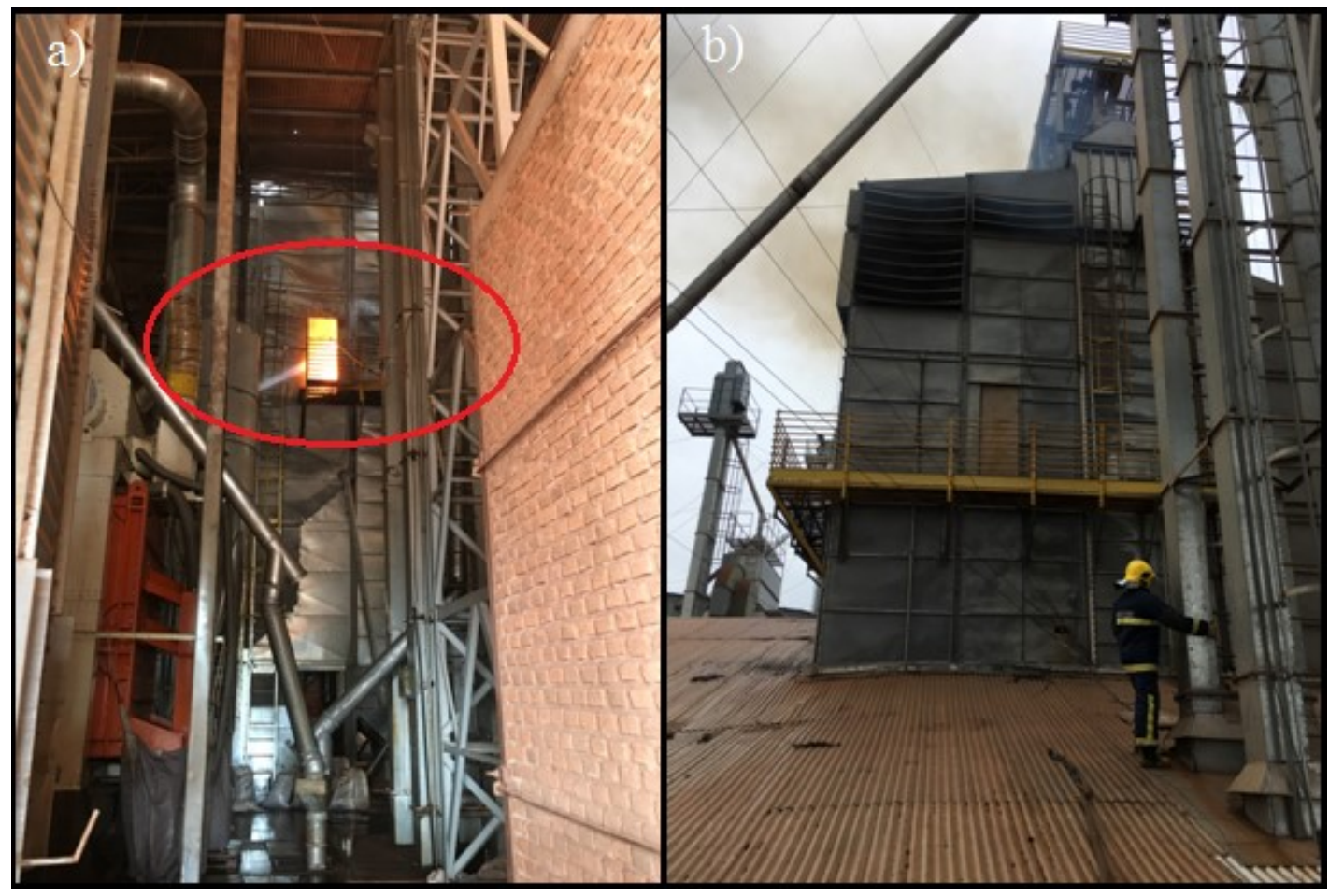

Fonte: Acervo do autor (2017)

Na Figura 12 se apresenta o histórico do tempo médio de duração de uma ocorrência de combate a incêndio em IBAG's. Para alcançar este resultado foram selecionadas de modo aleatório 50 ocorrências entre os anos de 2005 e 2017, das 495 registradas no SYSBM, com base no qual se pôde determinar o tempo médio de combate a incêndio em 5,5 horas. 
Revista Científica do Corpo de Bombeiros Militar de Pernambuco

XVIII Seminário Nacional de Bombeiros - Foz do Iguaçu PR

Vol.04 No11 - Edição Especial XVIII SENABOM - ISSN 2359-4829

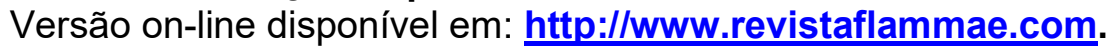

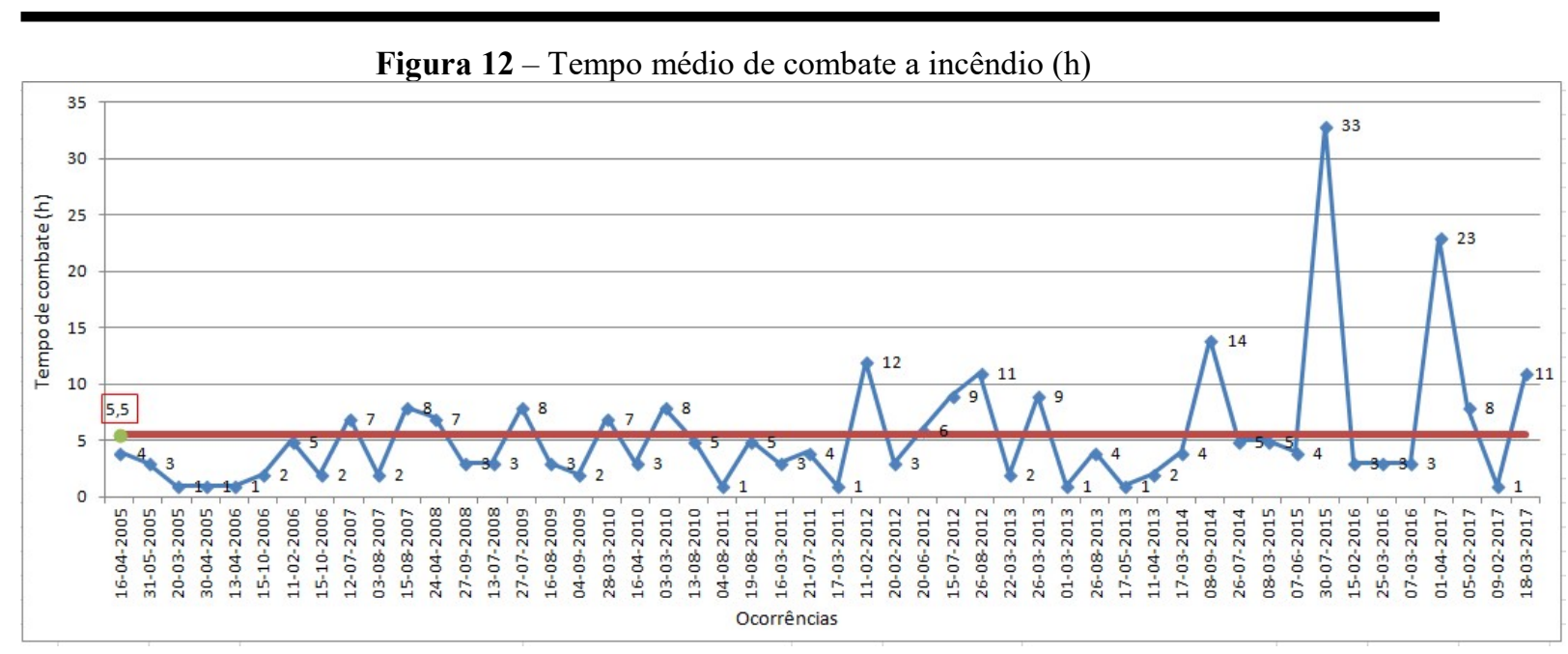

Fonte: SYSBM - Sistema de Registro de Ocorrências e Estatísticas do Corpo de Bombeiros do Paraná (2018)

$\mathrm{O}$ atendimento das ocorrências exigem longos períodos de trabalho, e acabam extenuando os bombeiros envolvidos. Esse fato é agravado pelo uso de equipamentos pesados, pelas elevadas temperaturas e pelos grandes esforços despendidos.

\section{CONCLUSÕES}

Quando comparado aos demais Estados da federação, o Paraná concentra grande quantidade de IBAG's. Com 2.819 unidades, esta em $2^{\circ}$ lugar, atrás apenas do Rio Grande do Sul, com 4.796.

A partir do ano de 2010 houve aumento significativo do número de registros de ocorrências desta natureza. As áreas de maior incidência estão localizadas nas regiões norte, oeste e sudoeste do Estado, regiões predominantemente agrícolas.

Os incêndios em secadores de grãos são a maioria em comparação aos demais equipamentos das unidades, respondendo por 77,24\% dos registros. Existe uma grande dificuldade no controle das chamas nestes locais devido a suas características construtivas. Por atingirem temperaturas muito altas durante os incêndios, os bombeiros devem ficar atentos a integridade estrutural dos secadores por haver risco de colapso. $\mathrm{O}$ método de abafamento e descarga de grãos para extinção das chamas, pode não 
Revista Científica do Corpo de Bombeiros Militar de Pernambuco XVIII Seminário Nacional de Bombeiros - Foz do Iguaçu PR

Vol.04 No11 - Edição Especial XVIII SENABOM - ISSN 2359-4829

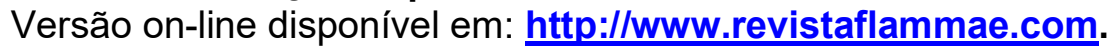

funcionar devido a formação de blocos fundidos dos próprios cereais, que entopem a bandeja de descarga.

As ocorrências de explosões de poeira, primárias e secundárias, requerem por parte dos bombeiros um entendimento de suas condições de existência. Os danos causados por estas modalidades de explosão são normalmente de grande monta. Do ponto de vista da prevenção se faz necessário: 1) Treinamento dos funcionários das unidades, inclusive terceirizados, sobre as causas e riscos das explosões da poeira; 2) Dimensionamento adequado de equipamentos e dispositivos anti explosão; 3) Programa permanente de limpeza das instalações.

O tempo médio do atendimento das ocorrências foi de 5,5 horas, gerando longas e cansativas jornadas de trabalho.

\section{REFERÊNCIAS}

CALLISTER, Jr., William D. Ciência e engenharia de materiais : uma introdução. Rio de Janeiro : LTC, 2008.

COMIL SILOS E SECADORES. Manual de operação e manutenção: Secadores de coluna COMIL. Versão 06/2011. Cascavel, PR, 2011. 40 p.

FLORENÇA, Valdir. Segurança contra incêndios em silos de armazenagem de grãos. 160 f. Centro de ciências da administração e socioeconômicas - ESAG - UDESC, Florianópolis, 2014.

GRIMWOOD, P. \& DEMEST, K. Tactical Firefighting, versão 1.1, Inglaterra: CEMEC, 2003.

PERSSON, Henry. Silo Fires: Fire extinguishing and preventive and preparatory measures. Swedish Civil Contingences Agency (MSB), 2013.

SÁ, Ary de. Explosões - O Perigo dos Grãos. Revista Proteção. Ed. 98. 1998. Disponível em: $<\mathrm{http} / / / \mathrm{ftp}$.feq.ufu.br/Luis_Claudio/Seguran\%C3\%A7a/Seguranca/explosaoperigodosgr aos.pdf >. Acesso em: 17 jul. 2018, 23:40h.

SILVA, Luis César. Explosões em Unidades Armazenadoras de Grãos. Nov. 1999. Disponível em:

$<$ http://www.agais.com/explosao.htm>. Acesso em: 17 jul. 2018, 23:47h. 